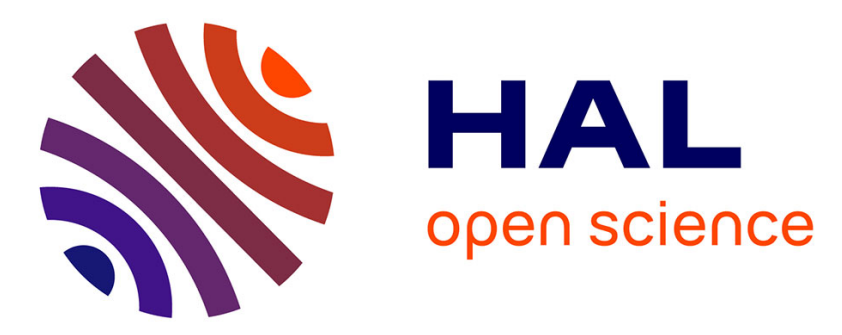

\title{
Awareness of disease state without explicit knowledge of memory failure in transient global amnesia.
}

Mathieu Hainselin, Peggy Quinette, Béatrice Desgranges, Olivier Martinaud, Vincent de La Sayette, Didier Hannequin, Fausto Viader, Francis Eustache

\section{- To cite this version:}

Mathieu Hainselin, Peggy Quinette, Béatrice Desgranges, Olivier Martinaud, Vincent de La Sayette, et al.. Awareness of disease state without explicit knowledge of memory failure in transient global amnesia.. Cortex, 2012, 48 (8), pp.1079-84. 10.1016/j.cortex.2012.02.003 . inserm-00667907

\section{HAL Id: inserm-00667907 https://www.hal.inserm.fr/inserm-00667907}

Submitted on 30 Aug 2012

HAL is a multi-disciplinary open access archive for the deposit and dissemination of scientific research documents, whether they are published or not. The documents may come from teaching and research institutions in France or abroad, or from public or private research centers.
L'archive ouverte pluridisciplinaire HAL, est destinée au dépôt et à la diffusion de documents scientifiques de niveau recherche, publiés ou non, émanant des établissements d'enseignement et de recherche français ou étrangers, des laboratoires publics ou privés. 


\section{Awareness of disease state without explicit knowledge of memory failure in transient global amnesia}

Mathieu Hainselin ${ }^{1,2,3,4}$, Peggy Quinette ${ }^{1,2,3,4}$, Béatrice Desgranges ${ }^{1,2,3,4}$, Olivier Martinaud ${ }^{6,7}$, Vincent de La Sayette ${ }^{1,2,3,5}$, Didier Hannequin ${ }^{6,7}$, Fausto Viader ${ }^{1,2,3,5}$, and Francis Eustache $e^{1,2,3,4}$

${ }_{1}$ Inserm, U1077, Caen, France

${ }_{2}$ Université de Caen Basse-Normandie, UMR-S1077, Caen, France

${ }_{3}$ Ecole Pratique des Hautes Etudes, UMR-S1077, Caen, France

${ }_{4}$ CHU de Caen, U1077, Caen, France

${ }_{5}$ CHU de Caen, Service de Neurologie, Caen, France

${ }_{6}$ Inserm, U1079, Rouen, France

${ }_{7}$ CHU de Rouen, U1079, Rouen, France

Correspondance to: Prof. Francis Eustache

Unité de recherche U1077, "Neuropsychologie et neuroanatomie fonctionnelle de la mémoire humaine",

CHU, Avenue de la Côte de Nacre, 14033 Caen Cedex 09, France

Tel.: +33(0)231065197

Fax: + 33(0)231065198

E-mail: neuropsycho@chu-caen.fr

Abbreviated form of the title: Emotional experience and awareness in TGA 


\section{ABSTRACT}

Introduction: Transient global amnesia (TGA) is a syndrome characterised by the rapid onset of antero- and retrograde amnesia, accompanied by temporal disorientation and iterative questioning. It is now established that the acute phase is associated with a raised level of anxiety and a depressed mood. We conducted a thorough investigation of patients' perceptions of their disease state, focusing on the links between their lack of explicit knowledge of amnesia during the acute phase and their emotional experience.

Methods: Explicit knowledge of memory deficits was assessed during TGA by means of an original scale inspired by Bisiach et al. (1986) and self-reported scales measuring patients' perceptions of their current memory and their cognitive and behavioural functioning. At the same time, we probed the patients' emotional experience (sources of worry, and levels of worry, anxiety and depression) via questionnaires. Data were collected from 20 patients in the acute phase, 16 in the peri-acute phase, 16 who were assessed the day after the episode and 14 healthy controls. Each patient underwent a follow-up examination two months later.

Results: Patients in the acute phase displayed a lack of explicit knowledge of their amnesia and overestimated their memory performances. They also expressed higher levels of worry and anxiety than controls, and a more depressed mood.

Conclusions: Although they were aware of their disease state, the TGA patients were unable to identify the nature of their memory deficits and overestimated their memory performances. These memory misperceptions and the inability to acknowledge memory failure occurred concomitantly with changes in the patients' emotional state. This particular pattern of awareness could be regarded as a reaction to the suddenness and massiveness of the amnesia.

Keywords: transient global amnesia; awareness; anxiety; worry; mood 


\section{Introduction}

Transient global amnesia (TGA) is a neurological syndrome occurring in middle-aged people and characterised by the sudden onset of massive anterograde amnesia, a more variable retrograde amnesia, temporal disorientation and iterative questioning. No consensus has yet been reached in PET studies of TGA patients, with abnormalities reported in the hippocampus, amygdala, lentiform nucleus or prefrontal cortex (Baron et al., 1994; Eustache et al., 1997; Guillery et al., 2002) during the acute and peri-acute phases. However, highly focal lesions confined to the CA1 field of the hippocampus have been detected on MRI and are considered to be the structural correlate of the amnestic deficit (Bartsch et al., 2010).

The clinical manifestations of TGA are still not perfectly understood and have yet to be integrated into a coherent whole. While the acute phase of amnesia is known to be associated with increased anxiety and a deterioration in mood (Merriam et al., 1992; Noël et al., 2008; Quinette et al., 2006a), little is known about the patient's emotional experience and awareness of amnesia. In TGA, some studies have reported either partial (Caplan, 1985) or complete (Evans, 1966; Härting and Markowitsch, 1996; Hodges and Warlow, 1990a; Regard and Landis, 1984) awareness of the deficit, with some patients being able not only to detect that something has gone wrong but also to identify their disorder as a memory deficit, and others displaying total unawareness of their amnesia (Stillhard et al., 1990; Tanabe et al., 1991; Trillet, 1990). This discrepancy could, in part, be explained by the timing or nature of the assessments administered (i.e., whether or not the patients were specifically questioned about their memory).

The present study therefore set out to explore 1) the patients' explicit knowledge of their memory deficits, general cognition and behaviour during the acute phase, and 2) the links between explicit knowledge of the memory deficit and emotional experience. 


\section{Methods}

\subsection{Participants}

Our sample was the largest ever for a neuropsychological study of TGA. It consisted of fifty-two TGA patients admitted to the emergency departments of Caen or Rouen University Hospital between January 2008 and March 2011. A control group consisted of 14 healthy people, matched with the TGA patients on age and level of education. All participants gave their written informed consent to the study, which was approved by the local ethics committee.

All the controls and thirty-five of the patients (fifteen during the acute phase, ten during the peri-acute phase and ten the day after the onset of the amnesia) were drawn from the cohort of a previously published study of prospective memory (Hainselin et al., 2011). Descriptive data are reported in Table 1. All the patients met the standard clinical criteria for diagnosing TGA (Hodges and Warlow, 1990b) and underwent a neurological examination, brain CT scans and electroencephalograms, all of which were normal, except for seven of them (four EEGs revealed minor abnormalities without epileptic features, and three CT scans revealed moderate, normal-for-age atrophy). Twenty patients were examined during the acute phase, sixteen others during the peri-acute phase and sixteen more the day after the onset of the amnesia. The end of the acute phase is difficult to pinpoint, as the recovery process is quite gradual (Quinette et al., 2006a). We therefore used several indicators (Noël et al., 2008): patients who no longer exhibited temporal disorientation or repetitive questioning, but still displayed moderate memory deficits, were included in the peri-acute phase group. Patients assessed more than 24 hours after onset of the symptoms were included in the "day-after" 
group. The mean duration of the episodes suffered by our 52 patients was 4 hours and 34 minutes $(S D=37 \mathrm{~min})$.

Episodic memory was assessed with the Encoding - Storage - Retrieval (ESR) test derived from Grober and Buschke's procedure (Grober and Buschke, 1987), which has been used and described in several previous studies of TGA (Eustache et al., 1999; Guillery et al., 2000; Guillery et al., 2001; Guillery et al., 2002; Quinette et al., 2003; Quinette et al., 2006b). We also tested executive functions using the Stroop test (inhibition) and the Trail Making Test (shifting; Godefroy, 2008). Results, reported in Table 1, confirmed that episodic memory was impaired, but executive functions were spared. Follow-up neuropsychological and neurological assessments, carried out roughly two months later (mean interval $=73.45$ days, $S D=8.59)$, attested to the absence of cognitive impairment.

\subsection{Assessment of explicit knowledge of memory deficit}

We used an observational method to measure explicit knowledge of amnesia during TGA.

We administered a novel scale inspired by the one developed by Bisiach et al. (1986) in the field of hemiplegia and designed specifically for TGA by our unit. This involved the experimenter asking the patients whether they knew about their memory deficit. If they did not, he asked them to perform a story recall task (which TGA patients always fail) to highlight the memory deficit. Patients were ranked on a scale of 0-3 (grades 2 and 3 reflected an inability to identify the cause of the disease state, i.e., the amnesia):

- Grade 0: the patient spontaneously complained of a memory impairment;

- Grade 1: the patient acknowledged a memory impairment after being prompted with a specific question about a memory issue; 
- Grade 2: the patient acknowledged a memory impairment after failing the story recall task;

- Grade 3: even after failing the story recall task, the patient still did not acknowledge a memory impairment.

\subsection{Self-perception assessment}

A self-report method was used to measure the memory, general cognition and behaviour of patients and controls.

They were asked to rate their current memory function, general cognition and behaviour on separate 4-point scales (detailed in Appendix 1).

\subsection{Emotional experience assessment}

In order to gauge possible emotional changes, we assessed anxiety and mood state in both controls and patients with the State-Trait Anxiety Inventory (STAI; Part 1 concerns state anxiety, Part 2 trait anxiety - Spielberger, 1983), a French adaptation of the Beck Depression Inventory (BDI; Beck et al., 1974) and the Adjective Mood Scale (Befindlichkeits-Skala, BfS; Von Zerssen et al., 1970).

Finally, we assessed the presence and nature of worries in TGA patients on a specially designed clinical scale developed by our unit. This comprised seven questions about their personal emotional experience during the TGA episode (detailed in Appendix 2). In these questions, the patients were asked to self-assess their worried state on a scale ranging from 1 (not at all worried) to 4 (very worried). 


\subsection{Statistical analysis}

The data from the explicit knowledge of amnesia assessment were analysed with a nonparametric chi-square test. Other data were subjected to a one-way ANOVA, with group as a between-participants factor. Tukey's post hoc tests were used to carry out paired comparisons.

We wanted to use correlations to study the link between measures of explicit knowledge of amnesia, self-perception and emotional experience. To increase the statistical power, we collapsed the acute and peri-acute groups (i.e., all the patients with an episodic impairment) into a single group of 36 individuals.

\section{Results}

\subsection{Assessment of explicit knowledge of memory deficit}

A lack of explicit knowledge of the memory deficit was found in 31 of the 36 patients (20 with grade 2 and 11 with grade 3 ) in the acute (11 with grade 2 and seven with grade 3 ) and peri-acute phases (nine with grade 2 and four with grade 3). There was a significant difference between grades, with grades 2 and 3 (that refer to a lack of explicit knowledge of the memory impairment) being more numerous for patients in the acute $\left(\chi^{2}=14.80 ; p=.002\right)$ and peri-acute $\left(\chi^{2}=10.50 ; p=.015\right)$ phases. These results are set out in Table 2 .

\subsection{Self-perception assessment}


Concerning the self-report scales, a significant group effect was found for memory, $F(3,62)=6.154, p=.0001$. There was no effect for general cognition or behaviour. Post hoc analyses showed that the acute-phase patients overestimated their memory performances compared with all the other groups (Table 3). There were no significant differences between the other groups.

\subsection{Emotional experience assessment}

No significant effect of group was found for the scores on the BDI, $F(3,62)=1.7850$, $p=.4593$, or the STAI-trait, $F(3,62)=.502, p=.6825$. We did, however, note a significant effect on scores on the STAI-state, $F(3,62)=29.747, p<.0001$, and the Bf-S, $F(3,62)=$ 4.2436, $p=.0086$. Post hoc analyses showed that patients in the acute phase scored higher on the STAI-state and the Bf-S than patients assessed the day after and healthy controls. Patients in the peri-acute phase scored higher than those assessed the day after and healthy controls, though only on the STAI-state.

There was a significant effect of group on the total score on the worry scale, $F(3,62)=$ $4.4265, p=.0087$. Post hoc analyses showed that acute-phase patients scored higher than the day-after group. Results are set out in Table 3. No significant difference was found concerning the nature of the worries.

\subsection{Correlations between the measures of explicit knowledge of amnesia, self- perception and emotional experience}

Positive correlations (for acute and peri-acute phases groups collapsed together) were found between the memory self-report scale and the Bf-S $(r=0.59 ; p<.01)$ and STAI-state $(r$ 
$=0.60 ; p<.01$ ) scores (i.e., the more patients overestimated their memory, the greater their depressed mood and state anxiety). No other significant correlations were found.

\section{Discussion}

Transient global amnesia (TGA) is a syndrome characterized by the sudden onset of antero- and retrograde amnesia, with temporal disorientation and iterative questioning. In this study, we demonstrated that, during an attack, TGA patients are unable to acknowledge their severe memory impairment, even when they are confronted with it. However, despite this lack of explicit knowledge regarding their memory deficits, they are worried about their situation, displaying a dissociation between their cognitive and emotional experiences during the episode. In short, they feel that something has gone wrong without knowing explicitly what it is. Concerning cognitive experience, we found that not only were patients in the acute phase unable to identify their memory impairment but they even overestimated their memory performance, compared with patients tested during the peri-acute phase and healthy controls. This misperception, restricted to memory and excluding general cognition and behaviour, was correlated with emotional changes (depressed mood and state anxiety).

These results indicate that during TGA, patients are unable to explicitly identify the root of their problem (i.e., a memory deficit). This lack of explicit knowledge of amnesia cannot simply be explained by the notion of "patients forgetting that they forgot" (see Agnew and Morris, 1998), as we found no correlation between the explicit knowledge score and the intensity of the amnesia, as measured with the episodic memory tests. However, despite this lack of explicit knowledge of the memory disturbance, there is some evidence that TGA patients are aware of their disease state. First, the repetitive questioning (Inzitari et al., 1997; Noël et al., 2008) observed during the acute phase can shed some useful light on patients' 
emotional experience of TGA. These stereotyped iterative questions can concern many different topics, but in each patient they will always be the same, driven by the immediate context (e.g., where they are, the last thing they did, the last event they encoded, the reason they are in hospital) and could be regarded as a way of expressing the uncertainties and worries they cannot understand. It is tempting to argue that patients are simply worried because they find themselves in hospital. In our opinion, however, the hospital environment is, at most, an additional source of anxiety. During TGA, patients are upset before they reach hospital, as consistently reported by their relatives. Second, patients who are alone at the onset of the episode - none of whom were included in our study because they did not strictly meet the TGA criteria (Hodges and Warlow, 1990b) - frequently call their closest relatives and evoke an unusual state, strengthening the idea that they are aware of the intensity of their anxiety and mood changes, and contrasting with their inability to identify cognitively and explicitly the origin of their problem. This suggests that there may be some implicit knowledge of the ongoing brain dysfunction that their consciousness is unable to grasp at the time, but which allows them to have a form of awareness. This hypothesis is compatible with previous experimental and clinical studies suggesting that focal lesions restricted to the medial temporal regions (probably the hippocampus, in the case of TGA; see Bartsch et al., 2010) are not sufficient to produce unawareness (Schacter, 1990). In the present study, we can also speculate that the integrity of the frontal areas (attested to by the normal performances on the executive tests) sustains implicit awareness of the disease state. A similar dissociation between implicit and explicit awareness for motor deficits has already been found in hemiplegia and could explain our patients' profile (Fotopoulou et al., 2010). Finally, these results raise the question of whether awareness that something is wrong with one's mind can occur without one realising what is wrong. 
Despite their inability to identify their major memory deficits, TGA patients are anxious and worried about their situation, and thus retain a form of self-coherence that allows them to realise that something has changed and is not quite right. This is consistent with the preservation of their personality and their accurate self-reports of behaviour and general cognition during the acute and peri-acute phases. We can also assume that it is this form of self-consciousness that prompts their iterative questioning and makes them seek help if they are alone. This is a specific characteristic of TGA, a "pure" memory syndrome, that is not found in other forms of amnesia, such as Korsakoff's syndrome or functional amnesia, in which patients are either totally unconcerned about their memory deficit (Pujol and Kopelman, 2003) or else develop defensive strategies. Given this distinctive characteristic of TGA patients, and in accordance with Levine's hypothesis (1990), we suggest that, despite their amnesia, TGA patients are able to understand that something is wrong through a process of self-observation and inference: they can observe their environment or themselves properly (at least their general cognition and behaviour) and have no intellectual impairment preventing them from making general inferences. However, a memory impairment, being a cognitive issue, is more difficult to identify than a physical problem (e.g., hemiplegia). Furthermore, as suggested by Levine (1990) for visual defects, the perception of a deficit is not always phenomenally immediate, especially if it appears suddenly, as with TGA.

Regarding the mood and state anxiety changes observed immediately after the onset of amnesia in this study, we can put forward two nonexclusive hypotheses concerning the origin of the emotional upset. First, it may be a consequence of a brain dysfunction (Mayberg et al., 1999), consistent with some PET studies reporting slight limbic dysfunction (Baron et al., 1994; Eustache et al., 1997; Guillery et al., 2002) during the acute and peri-acute phases. Second, the emotional upset may be a reaction to the suddenness of the amnesia, implicitly perceived, as supported by recent neuroimaging data in TGA pointing to very selective 
lesions in the CA1 field of the hippocampus (Bartsch et al., 2010), and so may not be a consequence of limbic dysfunction for all patients. Previous results for a large cohort could sustain both hypotheses, as they suggested the existence of different profiles for TGA patients (Quinette et al., 2006a). These two nonexclusive hypotheses will need to be confirmed by a systematic exploration of cognitive and emotional experiences, combined with anatomical and functional neuroimaging studies.

In conclusion, we highlighted the lack of explicit knowledge of memory deficits during TGA and a concomitant worry about the situation. We deliberately chose not to use the generic and polysemous term "anosognosia" (Hannesdottir et al., 2007), as the unique profile of TGA patients does not correspond to its most common definition ("unawareness of a disease state"). This novel pattern of results, concerning a particularly puzzling aspect of TGA, helps to refine our understanding of this intriguing syndrome. Other studies are now needed to undertake a more in-depth exploration of neuroanatomical aspects, metacognition and self-representations, and their links with cognitive and emotional factors in TGA.

\section{Acknowledgements}

The authors would like to thank Sandrine Bioux, Evangéline Bliaux, Carole Girard and Aurelija Juskenaite for collecting the data, and Dr Jacques Dayan for his helpful comments.

We are also grateful to the staff of the Accident \& Emergency Department, Neurology Units and Clinical Research Department at Caen University Hospital, and the Emergency Neurology Unit at Rouen University Hospital for their unstinting cooperation.

\section{Study funding}


INSERM managed the $\mathrm{PhD}$ funding of Mathieu Hainselin, undertaken by BasseNormandie Regional Council and by the Vicq d'Azyr association.

\section{Conflict of interests}

There is no competing interest. 


\section{Reference List}

Agnew SK and Morris RG. The heterogeneity of anosognosia for memory impairment in Alzheimer's disease: A review of the literature and a proposed model. Aging \& Mental Health, 2 (1): 7-19, 1998.

Baron JC, Petit-Taboué MC, Le Doze F, Desgranges B, Ravenel N, and Marchal G. Right frontal cortex hypometabolism in transient global amnesia. A PET study. Brain, 117 (3): 545$552,1994$.

Bartsch $\mathrm{T}$ and Deuschl G. Transient global amnesia: Functional anatomy and clinical implications. Lancet Neurology, 9 (2): 205-221, 2010.

Beck AT, Rial WY, and Rickets K. Short form of Depression Inventory: Cross validation. Psychological Reports, 34 (3): 1184-1186, 1974.

Bisiach E, Vallar G, Perani D, Papagno C, and Berti A. Unawareness of disease following lesions of the right hemisphere: Anosognosia for hemiplegia and anosognosia for hemianopia. Neuropsychologia, 24 (4): 471-482, 1986.

Caplan L. Transient global amnesia. In Frederiks JA (Ed.) Handbook of Clinical Neurology: Clinical Neuropsychology. Amsterdam: Elsevier Science, 1985: 205-217.

Eustache F, Desgranges B, Laville P, Guillery B, Lalevée C, Schaeffer S, de La Sayette V, Iglesias S, Baron JC, and Viader F. Episodic memory in transient global amnesia: Encoding, storage, or retrieval deficit? Journal of Neurology, Neurosurgery and Psychiatry, 66 (2): 148154, 1999.

Eustache F, Desgranges B, Petit-Taboue M, De La Sayette V, Piot V, Sable C, Marchal G, and Baron JC. Transient global amnesia: Implicit/explicit memory dissociation and PET assessment of brain perfusion and oxygen metabolism in the acute stage. Journal of Neurology, Neurosurgery \& Psychiatry, 63 (3): 357-367, 1997. 
Evans JH. Transient loss of memory, an organic mental syndrome. Brain, 89 (3): 539-548, 1966.

Fotopoulou A, Pernigo S, Maeda R, Rudd A, and Kopelman MA. Implicit awareness in anosognosia for hemiplegia: Unconscious interference without conscious re-representation. Brain, 133 (12): 3564-3577, 2010.

Godefroy O. Fonctions Exécutives et Pathologies Neurologiques et Psychiatriques. Marseilles: Solal, 2008.

Grober E and Buschke H. Genuine memory deficits in dementia. Developmental Neuropsychology, 3 (1): 13-36, 1987.

Guillery B, Desgranges B, de La Sayette V, Landeau B, Eustache F, and Baron JC. Transient global amnesia: Concomitant episodic memory and positron emission tomography assessment in two additional patients. Neuroscience Letters, 325 (1): 62-66, 2002.

Guillery B, Desgranges B, Katis S, de La Sayette V, Viader F, and Eustache F. Semantic acquisition without memories: Evidence from transient global amnesia. Neuroreport, 12 (17): 3865-3869, 2001.

Guillery B, Desgranges B, Piolino P, Laville P, de La Sayette V, and Eustache F. Extensive temporally graded retrograde amnesia for personal-episodic facts in transient global amnesia. Neurocase, 6 (3): 205-210, 2000.

Hainselin M, Quinette P, Desgranges B, Martinaud O, Hannequin D, de La Sayette V, Viader F, and Eustache F. Can we remember future actions yet forget the last two minutes? Study in TGA. Journal of Cognitive Neuroscience, 23 (12): 4138-4189, 2011.

Hannesdottir K and Morris RG. Primary and secondary anosognosia for memory impairment in patients with Alzheimer's disease. Cortex, 43 (7): 1020-1030, 2007. 
Härting C and Markowitsch HJ. Different degrees of impairment in anterograde/retrograde memory and recall/recognition performance in a transient global amnesic case. Neurocase, 2 (1): 45-49, 1996.

Hodges JR and Warlow CP. The aetiology of transient global amnesia. A case-control study of 114 cases with prospective follow-up. Brain, 113 (3): 639-657, 1990a.

Hodges JR and Warlow CP. Syndromes of transient amnesia: Towards a classification. A study of 153 cases. Journal of Neurology, Neurosurgery and Psychiatry, 53 (10): 834-843, 1990b.

Inzitari D, Pantoni L, Lamassa M, Pallanti S, Pracucci G, and Marini P. Emotional arousal and phobia in transient global amnesia. Archives of Neurology, 54 (7): 866-873, 1997.

Levine DN. Unawareness of visual and sensorimotor defects: A hypothesis. Brain and Cognition, 13 (2): 233-281, 1990.

Mayberg HS, Liotti M, Brannan SK, McGinnis S, Mahurin RK, Jerabek PA, Silva JA, Tekell JL, Martin CC, Lancaster JL, and Fox PT. Reciprocal limbic-cortical function and negative mood: Converging PET findings in depression and normal sadness. American Journal of Psychiatry, 156 (5): 675-682, 1999.

Merriam AE, Wyszynski B, and Betzler T. Emotional arousal-induced transient global amnesia. A clue to the neural transcription of emotion? Psychosomatics, 33 (1): 109-113, 1992.

Noël A, Quinette P, Guillery-Girard B, Dayan J, Piolino P, Marquis S, de La Sayette V, Viader F, Desgranges B, and Eustache F. Psychopathological factors, memory disorders and transient global amnesia. British Journal of Psychiatry, 193 (2): 1-7, 2008.

Pujol M and Kopelman MD. Psychogenic amnesia. Practical Neurology, 3 (5): 292-299, 2003. 
Quinette P, Guillery B, Desgranges B, de La Sayette V, Viader F, and Eustache F. Working memory and executive functions in transient global amnesia. Brain, 126 (9): 1917-1934, 2003.

Quinette P, Guillery-Girard B, Dayan J, de La Sayette V, Marquis S, Viader F, Desgranges B, and Eustache F. What does transient global amnesia really mean? Review of the literature and thorough study of 142 cases. Brain, 129 (7): 1640-1658, 2006 a.

Quinette P, Guillery-Girard B, Noël A, de La Sayette V, Viader F, Desgranges B, and Eustache F. The relationship between working memory and episodic memory disorders in transient global amnesia. Neuropsychologia, 44 (12): 2508-2519, $2006 \mathrm{~b}$.

Regard M and Landis T. Transient global amnesia: Neuropsychological dysfunction during attack and recovery in two "pure" cases. Journal of Neurology, Neurosurgery and Psychiatry, 47 (7): 668-672, 1984.

Schacter DL. Toward a cognitive neuropsychology of awareness: Implicit knowledge and anosognosia. Journal of Clinical and Experimental Neuropsychology, 12 (1): 155-178, 1990. Spielberger CD. Manual for the State-Trait Anxiety Inventory. Palo Alto, CA: Consulting Psychologists Press, 1983.

Stillhard G, Landis T, Schiess R, Regard M, and Sialer G. Bitemporal hypoperfusion in transient global amnesia: 99m-Tc-HM-PAO SPECT and neuropsychological findings during and after an attack. Journal of Neurology, Neurosurgery and Psychiatry, 53 (4): 339-342, 1990.

Tanabe H, Hashikawa K, Nakagawa Y, Ikeda M, Yamamoto H, Harada K, Tsumoto T, Nishimura T, Shiraishi J, and Kimura K. Memory loss due to transient hypoperfusion in the medial temporal lobes including hippocampus. Acta Neurologica Scandinavica, 84 (1): 22-27, 1991.

Trillet M. L'ictus amnésique. Le Concours Médical, 112 (26): 2370-2373, 1990. 
Emotional experience and awareness in TGA

Von Zerssen D, Koeller D.M, and Rey E.R. A scale for the objective evaluation of the state of subjective well-being as a method for longitudinal studies. Arzneimittel-Forschung, 20 (7): 915-918, 1970. 


\section{TABLES}

\begin{tabular}{|c|c|c|c|c|}
\hline & $\begin{array}{l}\text { Acute phase } \\
\text { patients ( } n= \\
\text { 20) }\end{array}$ & $\begin{array}{c}\text { Peri-acute } \\
\text { phase patients } \\
\qquad(n=16)\end{array}$ & $\begin{array}{l}\text { Day-after } \\
\text { patients } \\
(n=16)\end{array}$ & $\begin{array}{l}\text { Healthy } \\
\text { controls } \\
(n=14)\end{array}$ \\
\hline Gender: Women/Men & $15 / 5$ & $13 / 3$ & $12 / 4$ & $9 / 5$ \\
\hline Age in years: mean $(S D)$ & $65.45(6.62)$ & $62.13(5.46)$ & $65.87(7.64)$ & $64.80(7.40)$ \\
\hline $\begin{array}{l}\text { Level of education in } \\
\text { years: mean }(S D)\end{array}$ & $11.85(2.62)$ & $10.88(1.99)$ & $11.88(3.77)$ & $11.95(3.07)$ \\
\hline $\begin{array}{l}\text { Duration of acute phase } \\
\text { of TGA (in hours): mean } \\
(S D)\end{array}$ & $7.22(4.16)$ & $3.06(1.94)$ & $4.63(2.39)$ & / \\
\hline No. recurrent patients & $\begin{array}{l}3 \text { (second } \\
\text { episode) }\end{array}$ & $\begin{array}{l}2 \text { (second } \\
\text { episode) }\end{array}$ & 0 & / \\
\hline ESR free recall $\dagger$ & $\begin{array}{l}2.20 \\
(1.61)\end{array}$ & $\begin{array}{c}5.18 \\
(2.26)\end{array}$ & $\begin{array}{l}6.67 \\
(1.42)\end{array}$ & $\begin{array}{l}7.79 \\
(2.42)\end{array}$ \\
\hline TMT B: time $(S D)$ & $\begin{array}{l}102.57 \\
(44.51)\end{array}$ & $\begin{array}{c}97.1 \\
(35.12)\end{array}$ & $\begin{array}{l}108.21 \\
(51.08)\end{array}$ & $\begin{array}{l}89.07 \\
(57.27)\end{array}$ \\
\hline TMT B: errors $(S D)$ & $\begin{array}{l}0.48 \\
(0.52)\end{array}$ & $\begin{array}{l}0.51 \\
(0.56)\end{array}$ & $\begin{array}{l}0.78 \\
(0.74)\end{array}$ & $\begin{array}{l}0.33 \\
(0.35)\end{array}$ \\
\hline $\begin{array}{l}\text { Stroop interference: time } \\
(S D)\end{array}$ & $\begin{array}{l}123.14 \\
(63.52)\end{array}$ & $\begin{array}{l}125.34 \\
(45.55)\end{array}$ & $\begin{array}{l}122.89 \\
(25.42)\end{array}$ & $\begin{array}{l}102.14 \\
(32.99)\end{array}$ \\
\hline $\begin{array}{l}\text { Stroop interference: } \\
\text { errors }(S D)\end{array}$ & $\begin{array}{l}2.38 \\
(1.59)\end{array}$ & $\begin{array}{l}2.34 \\
(1.62)\end{array}$ & $\begin{array}{c}2.89 \\
(2.45)\end{array}$ & $\begin{array}{c}1.64 \\
(1.81)\end{array}$ \\
\hline
\end{tabular}


Table 1: Clinical, demographic and neuropsychological characteristics of individuals with TGA and controls.

ESR: Encoding - Storage - Retrieval

$\dagger$ ANOVA showed a significant group effect, $F(3,62)=39.402, p<.0001$, with acute-phase patients $<$ peri-acute phase patients $<$ day-after and control groups. 


\begin{tabular}{|l|c|c|}
\hline & $\begin{array}{c}\text { Acute phase } \\
\text { patients }(n=\end{array}$ & $\begin{array}{c}\text { Peri-acute } \\
\text { phase patients } \\
(n=16)\end{array}$ \\
\hline Grade 3 & 7 & 4 \\
(no. patients) & 11 & 9 \\
\hline Grade 2 & $20)$ & \\
\hline (no. patients) & & \\
\hline Grade 1 & & \\
\hline (no. patients) & & 0 \\
\hline (no. patients) & & \\
\hline
\end{tabular}

Table 2: Ratings on the explicit knowledge of memory deficit scale for amnesia scale for patients during TGA. Grades 2 and 3 correspond to the lack of explicit knowledge of the memory deficit. As neither patients assessed the day after or during follow-up nor healthy controls had any memory problems, there are no ratings on this scale for these groups. 


\begin{tabular}{|c|c|c|c|c|}
\hline & $\begin{array}{l}\text { Acute phase } \\
\text { patients ( } n= \\
\text { 20) }\end{array}$ & $\begin{array}{c}\text { Peri-acute } \\
\text { phase patients } \\
\qquad(n=16)\end{array}$ & $\begin{array}{l}\text { Day-after } \\
\text { patients } \\
(n=16)\end{array}$ & $\begin{array}{l}\text { Healthy } \\
\text { controls } \\
(n=14)\end{array}$ \\
\hline $\begin{array}{l}\text { Memory self-report } \\
\text { (raw score / 4) }\end{array}$ & $\begin{array}{l}3.70 * \\
(0.47)\end{array}$ & $\begin{array}{l}2.81 \\
(0.98)\end{array}$ & $\begin{array}{l}2.43 \\
(1.09)\end{array}$ & $\begin{array}{l}2.71 \\
(1.21)\end{array}$ \\
\hline $\begin{array}{l}\text { General cognition } \\
\text { self-report (raw score / 4) }\end{array}$ & $\begin{array}{l}3.17 \\
(1.67)\end{array}$ & $\begin{array}{l}3.28 \\
(2.13)\end{array}$ & $\begin{array}{l}3.45 \\
(1.72)\end{array}$ & $\begin{array}{l}3.05 \\
(2.02)\end{array}$ \\
\hline $\begin{array}{l}\text { Behaviour self-report } \\
\text { (raw score / 4) }\end{array}$ & $\begin{array}{r}2.92 \\
(1.78)\end{array}$ & $\begin{array}{l}3.25 \\
(2.05)\end{array}$ & $\begin{array}{r}3.44 \\
(1.98)\end{array}$ & $\begin{array}{l}3.38 \\
(1.54)\end{array}$ \\
\hline $\begin{array}{l}\text { BDI } \\
\text { (raw score / 39) }\end{array}$ & $\begin{array}{l}5.20 \\
(3.56)\end{array}$ & $\begin{array}{r}3.06 \\
(3.31)\end{array}$ & $\begin{array}{l}3.50 \\
(2.65)\end{array}$ & $\begin{array}{l}3.64 \\
(3.15)\end{array}$ \\
\hline $\begin{array}{l}\text { STAI-trait } \\
\text { (raw score / 80) }\end{array}$ & $\begin{array}{l}44.65 \\
(8.76)\end{array}$ & $\begin{array}{l}42.25 \\
(8.41)\end{array}$ & $\begin{array}{l}40.19 \\
(3.89)\end{array}$ & $\begin{array}{l}42.29 \\
(12.71)\end{array}$ \\
\hline $\begin{array}{l}\text { STAI-state } \\
\text { (raw score / 80) }\end{array}$ & $\begin{array}{l}59.95^{*} \\
(8.53)\end{array}$ & $\begin{array}{l}46.00 * \\
(10.63)\end{array}$ & $\begin{array}{l}31.69 \\
(10.76)\end{array}$ & $\begin{array}{l}27.57 \\
(5.32)\end{array}$ \\
\hline $\begin{array}{l}\text { Adjective mood scale / } \\
\text { Bf-S (raw score / 56) }\end{array}$ & $\begin{array}{l}26.65^{*} \\
(10.71)\end{array}$ & $\begin{array}{l}18.69 \\
(10.91)\end{array}$ & $\begin{array}{l}17.69 \\
(9.65)\end{array}$ & $\begin{array}{l}8.07 \\
(6.43)\end{array}$ \\
\hline Clinical worry scale & $\begin{array}{l}7.60 * \\
(2.03)\end{array}$ & $\begin{array}{l}5.60 \\
(1.50)\end{array}$ & $\begin{array}{l}3.13 \\
(2.04)\end{array}$ & / \\
\hline
\end{tabular}

Table 3: Patients' and controls' results, expressed as mean scores $(S D)$, for the self-reports of memory, general cognition and behaviour, anxiety and mood, and worries.

BDI: Beck Depression Inventory; STAI: State-Trait Anxiety Inventory.

* Significant difference between this group and the day-after and healthy control groups 
Emotional experience and awareness in TGA

- Significant difference between acute phase and peri-acute phase groups. 


\section{APPENDIX}

In your opinion, how is your memory currently?

Not normal at all $\begin{array}{llll}\mathbf{1} & \mathbf{2} & \mathbf{3} & \mathbf{4} \\ { } &{ } &{\text { Perfectly normal }}\end{array}$

In your opinion, how is your general cognition currently?

Not normal at all \begin{tabular}{llll}
$\mathbf{1}$ & $\mathbf{2}$ & $\mathbf{3}$ & $\mathbf{4}$ \\
\cline { 3 - 4 } & & & Perfectly normal
\end{tabular}

In your opinion, how is your behaviour currently?

12 Not normal at all

$3 \quad 4$

Perfectly normal

Appendix 1: Self-report scales for memory, general cognition and behaviour. 
Questions about worrying during the episode:

- Are you worried about your situation?

- Have you tried to remember what you did just before coming to hospital?

- Are you worried because you cannot remember what you did?

- Are you worried because you cannot remember what you have to do?

- Are you worried because you are afraid you may not recover your memory?

- Are you worried because you think you are acting weirdly?

- Are you worried because you are afraid of what people may think?

Appendix 2: Clinical worry scale 